\title{
Padrões de ação coletiva do empresariado industrial no Brasil: a agenda legislativa da CNI em 2017
}

\author{
Igor Sulaiman Said Felicio Borck
}

\section{RESUMO}

O objetivo dessa pesquisa, foi discutir a lógica da ação coletiva do empresariado industrial brasileiro, representado pela CNI, a luz das teorias que discutem a ação coletiva de grupos empresariais organizados no Brasil. Como objeto de pesquisa, tomamos o Seminário RedIndústria, realizado pela Confederação Nacional da Indústria (CNI), no ano de 2017. Como metodologia de pesquisa utilizamos a análise qualitativa $\mathrm{e}$ quantitativa de fontes primárias e secundárias, tanto documentos produzidos pela CNI, quanto a literatura especializada. Concluímos que o empresariado industrial reunido e representado pelo Seminário RedIndústria realiza uma ação coletiva eficiente, na medida em que produz uma agenda legislativa comum de interesses, monitora, acompanha e exerce pressão constante sobre o Congresso Nacional, através do Conselho de Assuntos Legislativos e da Gerência Executiva de Assuntos Legislativos, ambos aparelhos políticos da CNI de pressão sobre o Congresso Nacional. Por fim, constatamos que esse processo gera respostas eficientes do ponto de vista do empresariado industrial sobre suas demandas.

Palavras-chave: Agenda Legislativa; Congresso Nacional; Empresariado industrial; Confederação Nacional da Indústria (CNI).

\begin{abstract}
The objective of this research was to discuss the logic of the collective action of Brazilian industrial entrepreneurs, represented by $\mathrm{CNI}$, in light

${ }^{1}$ Cientista Social pela Universidade Federal do Paraná-UFPR, mestrando do Programa de Pós-Graduação em Ciência Política da UFPR, E-mail: iborcki@hotmail.com.
\end{abstract}


of the theories that discuss the collective action of organized business groups in Brazil. As research object, we took the Seminar RedIndústria, conducted by the National Confederation of Industry (CNI), in the year 2017. As a research methodology we used the qualitative and quantitative analysis of primary and secondary sources, both documents produced by $\mathrm{CNI}$ and literature specialized. We conclude that the industrial entrepreneurs assembled and represented by the RedIndustry Seminar carry out an efficient collective action, insofar as it produces a common legislative agenda of interests, monitors, monitors, and exerts constant pressure on the National Congress through the Legislative Affairs and Management Council Legislative Affairs Executive, both CNI's political apparatus of pressure on the National Congress. Finally, we find that this process generates efficient responses from the point of view of industrial entrepreneurs about their demands.

Keywords: Legislative Agenda; National Congress; Industrial Business; National Confederation of Industry (CNI).

Nessa pesquisa monográfica ${ }^{2}$ para conclusão do curso de Ciências Sociais da UFPR em 2017, na linha de formação de ciência política, procuramos debater o formato institucional da produção de uma ação coletiva da Confederação Nacional da Indústria (CNI), realizada no Seminário RedIndústria em 2017. Primeiramente, para tanto, analisamos algumas teses do campo da Ciência Política a respeito da organização política do empresariado industrial, com o intuito de melhor embasar nossa pesquisa empírica sobre este objeto.

Além disso, analisamos o formato institucional da CNI e de sua Diretoria de Relações Institucionais, com o objetivo de entender como o formato institucional que está por detrás da ação coletiva colabora para seu êxito, no sentido de produzir um ambiente favorável para a tomada de

\footnotetext{
${ }^{2}$ Para saber mais sobre essa monografia, ver: Borck, Igor Sulaiman Said Felicio. (2017) Os Padrões de Ação Coletiva do Empresariado Industrial no Brasil: Agenda Legislativa da CNI em 2017. UFPR. Disponível em http://www.humanas.ufpr.br/portal/cienciassociais/2017-2/
} 
decisão coletiva dos industriais representados pela CNI, no caso, em relação a agenda legislativa do Congresso Nacional.

Com esse objetivo, em primeiro lugar, estudamos os Conselhos Temáticos da CNI e sua importância para a tomada de decisão política da CNI, procurando mostrar como esses conselhos, inclusive o Conselho de Assuntos Legislativos (CAL), se constituem como um importante instrumento de tomada de decisão política da entidade em relação ao legislativo federal.

Em segundo lugar, analisamos a Gerência Executiva de Assuntos Legislativos ou Unidade de Assuntos Legislativos (COAL) da CNI, que se apresenta como um órgão técnico e administrativo diferente da CAL. Esse órgão é mais técnico e tem a função de seleção, monitoramento e avaliação das proposituras legislativa da agenda da CNI, e realiza esse trabalho através de um sistema online de acompanhamento legislativo, chamado Legisdata.

Em terceiro lugar, realizamos uma discussão sobre a agenda legislativa da CNI, mais especificamente, sobre seu histórico e formato, dando foco para 2017, relacionando-a com o formato do Seminário RedIndústria, para assim entender como os empresários industriais se reúnem, decidem e se organizam, e verificar a efetividade dessa tomada de decisão. Entendemos por efetividade, a capacidade do empresariado de definir uma agenda comum de interesses na esfera legislativa federal.

Por fim, analisamos os dados sobre a agenda legislativa da CNI no ano de 2017, buscando entender como os empresários se posicionam e o impacto deste posicionamento no Congresso Nacional através do lançamento da agenda da CNI aos congressistas. Neste sentido, consideramos a autoria das proposituras legislativas, os partidos dos parlamentares autores e a posição dos partidos no espetro ideológico.

Em suma, nosso trabalho busca contribuir para o debate sobre a lógica de ação coletiva do empresariado industrial brasileiro, a partir de 
um enfoque na organização política do empresariado industrial, entorno de uma agenda comum de interesses perante o legislativo federal, esfera importante da democracia em nosso país.

\section{Metodologia}

Utilizamos como fonte de pesquisa, o relatório da Confederação Nacional da Indústria (CNI), chamado Agenda Legislativa da Indústria 2017, que é o documento final, fruto do Seminário RedIndústria. Esse documento oficial da entidade, explicitou a posição política unificada dos empresários industriais representados pela CNI, sobre as proposituras legislativas em tramitação no Congresso Nacional que afetem seus interesses enquanto classe em 2017.

Outras fontes primárias utilizadas foram: o Estatuto da CNI, além do Regimento Interno do Seminário RedIndústria e do Manual das fichas de priorização da agenda legislativa, ambos de 2017, e que estão disponíveis no portal eletrônico da entidade. Estes três documentos revelaram a pesquisa, a forma com que o empresariado industrial se organiza no Seminário RedIndústria, dimensão fundamental para entender a lógica da ação coletiva do grupo.

Através da codificação do relatório Agenda Legislativa da Indústria de 2017, conseguimos extrair dados quantitativos sobre: tipo dos projetos, partidos, temáticas, autoria, tramitação e posição do empresariado industrial divididas em convergente, divergente ou ambas com ressalvas.

O tratamento metodológico dado ao Estatuto da CNI de 2017, ao Regimento Interno do Seminário RedIndústria e ao Manual das fichas de priorização da agenda legislativa de 2017, foi qualitativo, no sentido de que produzimos recortes a esses documentos que nos permitiram entender o formato institucional da tomada de decisão dos empresários industriais 
no Seminário RedIndústria. Em todos os esses relatórios, buscamos extrair informações, que pudessem revelar a amplitude do Seminário RedIndústria, no sentido de entender quem participa do seminário, como discute, como vota, como seleciona e como se posiciona.

Já as fontes secundárias utilizadas, foram referências bibliográficas especializadas, entorno da temática de ação coletiva do empresariado industrial. Buscamos trabalhos clássicos sobre o tema, os de Eli Diniz, Renato Boschi, Maria Antonieta Leopoldi e Murillo de Aragão, dialogando com trabalhos mais contemporâneos como o de Wagner Pralon Mancuso. Em suma, buscamos orientar nossa pesquisa empírica através de trabalhos clássicos e contemporâneos que trataram da mesma temática.

Por fim, utilizamos nessa pesquisa, métodos qualitativos e quantitativos de análise sobre os dados fornecidos pelas fontes primárias e secundárias, recortadas com objetivo de gerar análises sobre padrões de ação coletiva do empresariado industrial no Brasil no ano de 2017.

\section{Revisão de literatura}

Diversas pesquisas foram desenvolvidas pelo campo de pesquisa em ciência política sobre os padrões de ação política do empresariado brasileiro. Sabendo dessa vasta produção, e a fim de dar algum recorte metodológico a pesquisa, focamos nos trabalhos que buscaram discutir o empresariado industrial como um grupo organizado, que produz ação coletiva, e que de alguma forma exerce pressão sobre o Congresso Nacional. 
Pensando dessa forma, é que o primeiro trabalho que apresentamos é o de Eli Diniz e Renato Boschi, ${ }^{3}$ que no final da década 70, tomaram a "burguesia como objeto de estudo" com a intensão de verificar a correspondência entre os interesses do empresariado e as mudanças que marcaram o desenvolvimento industrial no Brasil, para assim estudar a visão dos industriais em relação à industrialização do período de 1930 no Brasil.

O objeto de análise de Eli Diniz e Renato Boschi (1979), foram algumas entidades de representação empresarial e agências estatais ligadas às políticas econômicas. Podemos destacar que, a preocupação foi, entre outras, defender a importância do protagonismo dos industriais no processo de industrialização e contrapor-se à tese da debilidade política deste grupo, o que não poderia ser considerado a priori, mas conhecido apenas "ao nível e uma análise empírica e mesmo conjuntural”.

Essas formas de análise, propostas por Eli Diniz e Renato Boschi orientaram esse trabalho monográfico, no sentido de constatar que não há uma real debilidade política do empresariado industrial em promover ação coletiva, que pelo contrário, não só esse grupo social consegue promover ação coletiva, como ela é eficaz, como poderemos verificar nos dados da pesquisa discutidos mais à frente no texto.

Outro trabalho clássico e relevante para os objetivos dessa pesquisa é o de Leopoldi (1992), ${ }^{4}$ onde a autora descreve que a ação do empresariado na década de 1930 e 40, foi marcada pelo intenso processo desenvolvimento no pós-II Guerra. Onde o empresariado queria participar do Estado e do planejamento e da centralização da estrutura de

3 Para saber mais sobre esse debate, ver: COSTA, P. R. N. e BORCK, I. S. S. F. “O capital privado nacional na literatura sobre desenvolvimento no Brasil" publicado nos Cadernos CEEED - UBA em 2015.

4 Para saber mais sobre esse debate, ver: COSTA, P. R. N. e BORCK, I. S. S. F. "O capital privado nacional na literatura sobre desenvolvimento no Brasil" publicado nos Cadernos CEEED - UBA em 2015. 
desenvolvimento industrial brasileiro. Isso se deu, por exemplo, pela construção das diversas Comissões Executivas, que buscavam se comportar como agências estatais de estímulo ao desenvolvimento industrial, separadas por setor, de maneira corporativa.

Outro trabalho clássico, mais atual sobre o tema, foi o realizado por Murillo de Aragão (1996), onde o autor buscar explicar como existem três polos ${ }^{5}$ de influência sobre o Congresso Nacional no Brasil, sendo um deles o próprio governo executivo federal, o segundo a classe trabalhadora e o terceiro o empresariado.

Segundo Aragão (1996) no terceiro polo de influência sobre o Congresso Nacional, formou-se no final da década de 90 início dos anos 2000, uma coalizão conhecida como "ação empresarial" que buscava pressionar o Congresso Nacional entorno de seus interesses de classe, conseguindo incentivos fiscais para melhorar a competitividade do setor.

Nesse trabalho, Aragão (1996) demostra que os empresários se organizam a fim de produzir ganhos coletivos para o seguimento industrial, mostrando que a tese da debilidade política do empresariado não se confirma no Brasil pós-redemocratização.

Um outro trabalho se mostrou fundamental e mais contemporâneo, para orientar essa pesquisa, que foi o realizado por Mancuso (2004), ${ }^{6}$ que estava preocupado em saber como um grupo, formado por atores heterogêneos, com interesses diversos, conseguiu construir, uma forma de ação coletiva eficiente, considerada de sucesso,

\footnotetext{
${ }^{5}$ Segundo Aragão: "Grosso modo, três polos de influência gravitavam em tomo de um Congresso pouco disposto a manifestar-se acerca de temas polêmicos às portas das eleições: governo, sindicatos de trabalhadores e empresariado." (ARAGÃO - 1996, p. 154).

${ }^{6}$ Segundo Mancuso: "Como explicar o fato de a indústria no Brasil, em meados da década de 9o, ter sido capaz de superar os problemas de ação coletiva típicos de um grupo formado por muitos atores heterogêneos e de adotar uma agenda comum formada por temas que superam as clivagens que dividem as empresas em função da competição pelo mercado, ou do seu porte, ou do ramo de atividade em que atuam? Como explicar, enfim, que a redução do custo Brasil se tenha constituído na síntese da agenda política do empresariado industrial?" (MANCUSO - 2004, p. 506).
} 
porque conseguiu - conforme demostrou o autor - reduzir o Custo Brasil para o ambiente de negócios industriais, ou seja, construíram uma agenda positiva para o país, voltada aos interesses da indústria nacional, em conjunto com o congresso nacional ao longo de 1996 a 2003.

Nesse sentido, o autor procurou estudar as proposituras legislativas mapeadas pela CNI, desde do início da agenda legislativa da entidade, que começa em 1996, e foi analisada até $2003 \cdot{ }^{7}$ Uma das variáveis mais importantes trabalhadas por Mancuso (2004) neste trabalho, é chamada de Custo Brasil, ${ }^{8}$ que pode ser entendida, como um conjunto de medidas adotadas pelo país, que pode aumentar os custos da competitividade industrial nacional ou diminuir esses custos.

Quando o Custo Brasil é reduzido pelo Congresso Nacional, por exemplo, aumenta a competitividade da indústria nacional, gerando mais desenvolvimento econômico para o país. Quando o Custo Brasil é aumentado, diminui a competitividade da indústria nacional, e consequentemente menor é o desenvolvimento econômico nacional, pois o desempenho industrial está imbricado na ideia de desenvolvimento econômico.

\footnotetext{
${ }^{7}$ Segundo Mancuso: "Os casos focalizados são os projetos que figuram nas Agendas Legislativas publicadas entre 1996 e 2003 e cuja tramitação foi encerrada até o dia 23 de dezembro de 2003, último dia de trabalho do parlamento brasileiro naquele ano." (MANCUSO - 2004, pp. 519).

${ }^{8}$ Segundo Mancuso: "Em maio de 1995, industriais de todo o país reuniram-se com deputados federais e senadores filiados a partidos políticos de diversas tendências ideológicas na sede da Confederação Nacional da Indústria - CNI, em Brasília, para participar do seminário Custo Brasil Diálogo como Congresso Nacional. Desde então, e até hoje, reduzir o custo Brasil tornou se a expressão que resume a principal demanda dirigida pelo empresariado industrial ao poder público para favorecer o crescimento econômico do país, em geral, e o fortalecimento da indústria, em particular. Custo Brasil é uma expressão utilizada não apenas por empresários, mas também por políticos, por acadêmicos, pela imprensa e pelo público em geral, para designar fatores que prejudicam a competitividade das empresas do país diante de empresas situadas em outros países. $\mathrm{Na}$ concepção utilizada neste artigo, seis fatores compõem o custo Brasil: excesso e má qualidade da regulação da atividade econômica; legislação trabalhista inadequada; sistema tributário que onera a produção; elevado custo de financiamento da atividade produtiva; infraestrutura material insuficiente; infraestrutura social deficiente (CNI, 1996a; 1998a)." (MANCUSO - 2004, p. 505).
} 
Essa ideia de Custo Brasil, foi construída, pela primeira vez, no ano de 1995, através do seminário “Custo Brasil diálogo com o Congresso Nacional", promovido pela CNI, que reuniu deputados federais, senadores, partidos políticos e outras entidades representativas dos industriais brasileiros, com a finalidade de construir um ambiente de negócios industriais, mais favorável a indústria nacional, representada pela CNI.

Para Mancuso (2004), esse momento ${ }^{9}$ foi importantíssimo para indústria nacional, pois conseguiu dar mais competitividade à indústria da década de 9o, que passava por inúmeras crises. Segundo o autor, ao realizar essa ação coletiva, as entidades de representação dos interesses dos industriais brasileiros foram bem-sucedidas e conseguiram ao longo daquela década reduzir o Custo Brasil, e consequentemente melhorar a competitividade da indústria nacional e assim gerar mais desenvolvimento econômico para o país.

Para Mancuso (2004), o aumento da concorrência no mercado industrial brasileiro da década de 9o, em combinação com o aumento no custo da competitividade das indústrias brasileiras, foram condições essenciais, mas não únicas, para construção de uma agenda política comum entre os industriais brasileiros. Segundo Mancuso (2004) a forma de organização das entidades ${ }^{10}$ políticas que representam os interesses dos

\footnotetext{
${ }^{9}$ Segundo Mancuso: "Em síntese, importa mostrar que a concorrência no setor industrial brasileiro se tornou mais acirrada ao longo da década de 1990. Expostas ao novo cenário, várias empresas não puderam subsistir e sucumbiram às fusões e aquisições. Muitas empresas, por outro lado, responderam com estratégias de ajuste e com elevação da produtividade. A competitividade tornou-se, portanto, a palavra-chave para a sobrevivência nesse ambiente de menor proteção. As empresas e as associações empresariais que pugnam pela redução do custo Brasil estão convencidas de que esta medida teria repercussão positiva sobre a competitividade industrial." (MANCUSO 2004, pp. 510).

${ }^{10}$ Segundo Mancuso: "O acirramento da concorrência e o desafio da competitividade são condições necessárias, mas não suficientes para a formação de uma agenda política comum centrada na redução do custo Brasil. Outro elemento que viabilizou a definição da agenda foi o trabalho coletivo das organizações que representam os interesses da indústria, coordenado pela CNI, entidade de cúpula do setor." (MANCUSO - 2004, pp. 510).
} 
industriais brasileiros, como a CNI e as federações de indústria de todo país, foram fundamentais para viabilizar a construção dessa agenda legislativa.

Mancuso (2004) buscou entender a dinâmica ${ }^{11}$ de organização das entidades entorno da agenda legislativa da indústria, e mostrou em seu artigo, como a agenda legislativa da indústria é divulgada anualmente desde 1996, na forma de relatório público, que nessas publicações, são expressas as posições da entidade com relação a cada propositura legislativa em pauta no congresso nacional, que de alguma forma, afetem a indústria nacional, e consequentemente o cálculo do Custo Brasil.

A preparação da agenda legislativa da CNI, é realizada por uma rede de entidades chamada RedIndústria, que vão desde da própria CNI e as federações de indústria de cada Estado brasileiro, até uma média de sessenta associações industriais nacionais, para discussão e construção da agenda legislativa de cada ano, que será posteriormente publicada nesse fórum.

Uma outra questão fundamental para Mancuso (2004), é discutir, através de seu trabalho, com os autores da tese da debilidade ${ }^{12}$ política da indústria, pois segundo o autor, parece que todo o esforço realizado pela CNI, contraria a tese da incapacidade de organização política do

11 Segundo Mancuso: "Com efeito, a CNI divulga anualmente, desde 1996, a Agenda Legislativa da Indústria, publicação que exprime a posição do setor diante de proposições legislativas que tramitam no Congresso Nacional e cuja aprovação, reforma ou rejeição teria o potencial de reduzir o custo Brasil ou impedir o seu aumento. A preparação das agendas legislativas é coordenada pela CNI e realizada pela RedIndústria, rede de organizações empresariais que abrange, além da própria CNI, as federações da indústria de todos os estados brasileiros e do Distrito Federal, assim como dezenas de associações setoriais de abrangência nacional." (MANCUSO - 2004, p. 510 e 511).

12 Segundo Mancuso: "A constatação de que os industriais desempenham um vultoso trabalho conjunto para identificar os projetos de maior impacto sobre o custo Brasil, definir uma posição comum e promover esta posição durante o processo legislativo contraria a tese da debilidade política da indústria no Brasil, defendida com vigor em numerosos trabalhos recentes e que tem atingido o status de sabedoria convencional sobre o assunto na literatura internacional (Schneider, 1997a; 1997b; 1998; 2002; Weyland, 1998a; 1998b; 2001; Kingstone, 2001; Power e Doctor, 2002)." (MANCUSO - 2004, p. 511). 
empresariado industrial, pois essas entidades empresariais, conseguem promover uma ação coletiva unificada e coesa, através da CNI. Essa ação, se materializa na forma de uma pauta bem-sucedida de diálogo com o Congresso Nacional. Que na avaliação de Mancuso (2004) obteve êxito, porque conseguiu reduzir o Custo Brasil no período estudado pelo autor. Esse conjunto de fatores parecem fragilizar as teses da debilidade política do empresariado industrial.

Mancuso (2004) se contrapõe ${ }^{13}$ as posições de Olson (1982), que argumentou que o empresariado industrial era "fragmentado em numerosos coalizões distributivas", e as ideias de Tullock (1993) que diziam que os empresários industriais preferiam buscar benefícios particulares perante o poder público do que em coletivo, pois o custo do individualismo industrial era menor do que o coletivo, comparado aos ganhos, e que principalmente não conseguem vislumbrar o bem público, do ganho coletivo ao longo prazo.

Segundo os autores das teses da debilidade política do empresariado, os industriais buscam a defesa de seus interesses setoriais e particulares ${ }^{14}$ perante o Estado, realizando uma ação chamada de rentseeking, que permite ganhos setoriais exclusivistas, por parte de setores privilegiados da economia industrial nacional. Isso ocorre, porque a

${ }^{13}$ Segundo Mancuso: "Fragmentado em numerosas coalizões distributivas (Olson,1982), o empresariado industrial empenha os recursos políticos à sua disposição em rent-seeking (Tullock, 1993), ou seja, para arrancar do poder público toda a sorte de vantagens particulares, tais como tratamento tributário favorecido, crédito subsidiado com taxas de juros diferenciadas, proteção especial contra a competição, entre outras. Os benefícios criados artificialmente por decisões casuísticas como essas são apropriados com exclusividade pelas empresas e segmentos industriais privilegiados. A intenção de agir de forma tão estreita é reforçada pela constatação de que o custo da ação política necessária para alcançar os enormes benefícios exclusivos é sempre menor do que o custo da mobilização da indústria como um todo." (MANCUSO - 2004, p. 512).

${ }^{14}$ Segundo Mancuso: "Em sua busca incessante por privilégios, as organizações empresariais setoriais não demonstram nenhum interesse pelo impacto que as medidas defendidas porventura irão exercer sobre o público em geral. Do mesmo modo, as associações atomizadas não dispensam nenhuma atenção para as consequências de suas demandas sobre as finanças públicas e a estabilidade da economia do país." (MANCUSO - 2004, p. 512). 
lógica dessa ação, se baseia na ideia de que o ganho coletivo é mais oneroso do que o ganho particular ou setorial, que é mais exclusivo e vantajoso.

Nesse sentido os industriais preferem o esforço setorial e não coletivo. Em suma, o argumento desses autores mostra, que os industriais na busca de privilégios estatais, se dividem e deturpam a demanda estatal, e ao fazê-lo não percebem as consequências de suas ações para competitividade do setor industrial brasileiro.

Não ignorando esses argumentos, Mancuso (2004) mostra como essa realidade de fragmentação cria dificuldades na ação coletiva dos industriais, porém não a impede de acontecer e se consolidar mais ao longo dos anos desde da década 90. Apesar da falta de representatividade ${ }^{15}$ das entidades estaduais, como por exemplo a Federação das Indústrias do Estado de São Paulo (FIESP) e da entidade nacional, a Confederação Nacional da Indústria (CNI), os industriais vem criando um ambiente propício para ação coletiva coordenada.

Quando os industriais brasileiros se reúnem anualmente no Seminário RedIndústria, promovido pela CNI, em conjunto com as Federações de Indústria, de todos os Estados brasileiros, e as Associações Setoriais de todos os seguimentos industriais nacionais, desde meados da década 90 até hoje, e definem um pauta única de interesses coletivos, com posições políticas unificadas, com relação aos proposituras legislativas em tramitação no Congresso Nacional, isso mostra um enorme esforço

\footnotetext{
${ }^{15}$ Segundo Mancuso: “A tendência centrífuga poderia ser contrabalançada pela atuação das entidades empresariais de maior abrangência, como a CNI e a Federação das Indústrias do Estado de São Paulo-FIESP. Isto não ocorre, no entanto, porque essas entidades são pouco representativas. Tanto a FIESP- que representa os industriais do estado mais industrializado do país - quanto a CNI - que representa toda a indústria em âmbito nacional - são associações que pertencem ao sistema corporativista. Graças à legislação corporativista, associações de grau inferior de diferentes níveis de relevância econômica têm importância equivalente na vida política interna das associações de grau superior como a FIESP e a CNI." (MANCUSO - 2004, p. 512).
} 
coletivo de ação coordenada de organização da representação de interesses de todos os seguimentos industriais.

A construção coletiva ${ }^{16}$ no Seminário RedIndústria, da agenda legislativa da indústria tem por objetivo corrigir problemas de competitividade dos seguimentos industriais e trazer benefícios públicos, do Estado brasileiro para o seguimento industrial como um todo, uma ação coletiva visando um ganho coletivo. Essa ação coletiva de construção, acompanhamento e pressão, feita pelos empresários industriais, através da CNI, demonstra como apesar a fragmentação do seguimento, eles são capazes se superar esses problemas e promoverem ações coletivas de sucesso perante do Estado Brasileiro, que promovem ganhos coletivos.

A partir da exposição desses trabalhos clássicos e contemporâneos sobre o empresariado brasileiro, é que propomos analisar o empresariado industrial no Brasil em 2017, buscando entender a partir dos dados da pesquisa em confronto com a literatura se o empresariado industrial brasileiro consegue produzir ação coletiva eficiente, do ponto de vista deles enquanto grupo social.

\section{Discussão dos resultados}

Quando analisamos os dados produzidos por essa pesquisa, notamos que a pauta mínima, ou seja, a prioridade da $\mathrm{CNI}$, está mais conectada com Poder Executivo Federal e o Senado da República, que são os maiores autores de projetos em convergência ou em convergência com ressalvas, com a posição da CNI em 2017, do que a Câmara dos Deputados.

\footnotetext{
${ }^{16}$ Segundo Mancuso: "Não obstante a enorme fragmentação do empresariado industrial, e o impulso centrífugo decorrente desta fragmentação, pelo menos desde meados da década de 1990 a indústria vem realizando um grande trabalho coletivo para definir e defender uma posição comum em relação a propostas legislativas que tramitam no Poder Legislativo federal e cuja aprovação, reforma ou rejeição pode contribuir para a solução de problemas que afetam negativamente a competitividade de todo o segmento." (MANCUSO - 2004, p. 514).
} 
No total de 7 projetos da pauta mínima, 3 são do Poder Executivo Federal e 3 do Senado da República, e somente 1 da Câmara dos Deputados. É importante salientar, que todos os projetos da pauta mínima da CNI, independentemente de autoria estavam em convergência ou convergência com ressalvas com o posicionamento da CNI.

Quando analisamos todos os projetos da agenda de 2017, independentemente se fazem ou não parte da pauta mínima, notamos o mesmo padrão, que o Poder Executivo Federal e o Senado da República propõem mas projetos em convergência ou convergência com ressalvas do que a Câmara dos Deputados, que pelo contrário, propõe mais projetos divergentes ou divergentes com ressalvas com a CNI.

O Senado da República propôs 19 projetos em convergência ou convergência com ressalvas, contra apenas 4 divergentes ou divergentes com ressalvas. O Poder Executivo Federal propôs 5 projetos em convergência ou convergência com ressalvas, contra apenas 1 divergente ou divergente com ressalvas. Já a Câmara dos Deputados propôs 15 projetos em convergência ou convergência com ressalvas, contra 17 divergentes ou divergentes com ressalvas. Conforme podemos analisar com detalhes na tabela 1 abaixo. 
TABELA O1: AUTORIA DAS PROPOSITURAS LEGISLATIVAS VERSUS

POSICIONAMENTO POLÍTICO INSTITUCIONAL DA CNI EM 2017 VERSUS

PAUTA MÍNIMA DA CNI:

\begin{tabular}{|c|c|c|c|c|c|}
\hline & & & \multicolumn{2}{|c|}{ Posicionamento } & \multirow[b]{2}{*}{ Total } \\
\hline & a Mínima & $\mathrm{CNI}$ & $\begin{array}{c}\text { Convergente } \\
\text { ou } \\
\text { Convergente } \\
\text { com ressalvas }\end{array}$ & $\begin{array}{c}\text { Divergente } \\
\text { ou } \\
\text { Divergente } \\
\text { com } \\
\text { ressalvas }\end{array}$ & \\
\hline \multirow{4}{*}{ Sim } & & Câmara & 1 & - & 1 \\
\hline & Autoria & & 3 & & 3 \\
\hline & & $\begin{array}{c}\text { Poder } \\
\text { Executivo }\end{array}$ & 3 & - & 3 \\
\hline & \multicolumn{2}{|c|}{ Total } & 7 & - & 7 \\
\hline \multirow{4}{*}{ Não } & \multirow{3}{*}{ Autoria } & Câmara & 14 & 17 & 31 \\
\hline & & Senado & 16 & 4 & 20 \\
\hline & & $\begin{array}{c}\text { Poder } \\
\text { Executivo }\end{array}$ & 2 & 1 & 3 \\
\hline & & & 32 & 22 & 54 \\
\hline \multirow{4}{*}{ Total } & Autoria & Câmara & 15 & 17 & 32 \\
\hline & & Senado & 19 & 4 & 23 \\
\hline & & $\begin{array}{c}\text { Poder } \\
\text { Executivo }\end{array}$ & 5 & 1 & 6 \\
\hline & \multicolumn{2}{|c|}{ Total } & 39 & 22 & 61 \\
\hline
\end{tabular}

Fonte: Borck, I. S. S. F. (2017)

Outro dado relevante, encontrado na pesquisa, mostra que quando cruzamos a autoria das proposituras legislativas com o dado sobre novas normas jurídicas, percebemos que o Poder Executivo Federal produz mais decisões legislativas do que as casas legislativas, ou seja, de 
61 projetos da agenda legislativa, apenas 4 viraram nova norma jurídica, e delas todas eram de autoria do Poder Executivo Federal, evidenciando o poder de agenda e decisão do Poder Executivo com relação a outros poderes. Conforme podemos verificar atentamente na tabela 2 abaixo:

\section{TABELA O2: AUTORIA DAS PROPOSITURAS LEGISLATIVAS VERSUS NOVA NORMA JURÍDICA:}

\begin{tabular}{|c|c|c|c|c|}
\hline & & \multicolumn{2}{|c|}{$\begin{array}{l}\text { Nova Norma } \\
\text { Jurídica }\end{array}$} & \multirow[b]{2}{*}{ Total } \\
\hline & & Sim & Não & \\
\hline \multirow{3}{*}{ Autoria } & $\begin{array}{l}\text { Câmara dos } \\
\text { Deputados }\end{array}$ & o & 32 & 32 \\
\hline & Senado da República & o & 23 & 23 \\
\hline & $\begin{array}{l}\text { Poder Executivo } \\
\text { Federal }\end{array}$ & 4 & 2 & 6 \\
\hline \multicolumn{2}{|c|}{ Total } & 4 & 57 & 61 \\
\hline
\end{tabular}

Fonte: Borck, I. S. S. F. (2017)

\section{Conclusão}

Após discutir os dados, concluímos que o formato institucional da CNI, conforme demostramos ao longo do texto, permite promover uma ação coletiva eficaz, no sentido de criar uma agenda comum de interesses legislativos de atores políticos heterogêneos, no caso, os empresários industriais que atuam no mercado nacional.

Os resultados colocam em dúvida as teorias da debilidade política do empresariado inspiradas em Olson (1999) e Tullock (1993) entre outros autores e indicam que outras teorias, como as de Eli Diniz e Renato Boschi (1978), Maria Antonieta Leopoldi (2000), Murillo de Aragão (1996) e Wagner Pralon Mancuso (2004 e 2007) fazem mais sentido para 
entender a ação política do empresariado industrial, do que as teses sobre debilidade política do ator.

Os dados sobre a agenda legislativa de 2017 revelaram um alto grau de convergência entre a produção legislativa e os interesses da CNI, apresentados em sua agenda legislativa. O que pode nos indicar que há um alto grau de satisfação do empresariado industrial e o regime democrático, o que implica em uma valorização da democracia por esse seguimento social detentor do capital privado industrial nacional.

Os dados ${ }^{17}$ também revelam que apesar de todo aparato organizacional da CNI e seu alto investimento político e técnico no legislativo federal, as decisões legislativas são custosas e difíceis, ou seja, no curto prazo podem representar um fracasso, mas, no longo prazo, se mostram eficientes e duradouras, pois são esforços cumulativos e repetidos em todo ano legislativo. A CNI organiza o Seminário RedIndústria desde 1996, o que mostra um alto investimento técnico e político ao longo dos anos, ou seja, os resultados veem a longo prazo e não no curto prazo.

Por fim, os resultados de nossa pesquisa sugerem algumas questões que se colocam para estudos futuros:

1. A necessidade de entender melhor a relação entre as decisões legislativas e a posição da CNI, através de uma análise de correspondência entre as posições da CNI e do Congresso Nacional, em uma série histórica, que abranja mais que um ano. Entendemos por correspondência, o encontro entre a posição política da CNI e da decisão legislativa produzida pelo Congresso Nacional.

${ }^{17}$ Notamos que no ano de 2017 a CNI incluiu em sua agenda 61 proposituras e que dessas, somente, 4 viraram nova norma jurídica, o que mostra que os resultados do alto investimento veem ao longo prazo, e não no curto prazo, conforme podemos verificar nos dados da tabela o6 da página 37. 
2. A necessidade de analisar o grau de efetividade da ação coletiva promovida pela CNI com relação a produção legislativa feita pelo Congresso Nacional através de análises quantitativas e estudos de caso.

\section{REFERÊNCIAS}

ARAGÃO, Murillo de. A Ação dos Grupos de Pressão nos Processos Constitucionais Recentes no Brasil. Revista de Sociologia e Política, n. 6-7, 1996.

CONFEDERAÇÃO NACIONAL DA INDÚSTRIA. Unidade de Assuntos Legislativos. Agenda Legislativa da Indústria 2017. Organizadores: Marcos Borges de Castro, Godofredo Franco Diniz, Frederico Gonçalves Cezar - Brasília. 2017

DINIZ, E. Empresário, Estado e capitalismo no Brasil (1930-1945). Rio de Janeiro: Editora Paz e Terra. 1978.

DINIZ, E.; BOSCHI, R. R. Empresariado Nacional e Estado no Brasil. Rio de Janeiro: Editora Forense Universitária. 1978.

LEOPOLDI, Maria Antonieta P. Política e Interesses na Industrialização Brasileira: As Associações Industriais, a Política Econômica e o Estado. São Paulo: Paz e Terra.20oo.

MANCUSO, Wagner Pralon. O Empresariado como ator político no Brasil: balanço da literatura e agenda de pesquisa. Revista de Sociologia e Política, n. 28, 2007.

MANCUSO, Wagner Pralon. O lobby da indústria no Congresso Nacional: empresariado e política no Brasil contemporâneo. Dados, v. 47, n. 3, p. 505-547, 2004.

OLSON, Mancur. A lógica da ação coletiva. São Paulo: Edusp. 1999.

TULLOCK, Gordon., Rent-Seeking. London, Edward Elgar Publishing Limited, 1993. 